\title{
Functionalization of carboxylated multiwall nanotubes with imidazole derivatives and their toxicity investigations
}

This article was published in the following Dove Press journal:

International Journal of Nanomedicine

2 November 2010

Number of times this article has been viewed

\author{
Javad Azizian' \\ Hasan Tahermansouri' \\ Esmaeil Biazar ${ }^{2}$ \\ Saeed Heidari ${ }^{3}$ \\ Davood Chobfrosh Khoei' \\ 'Department of Chemistry, Science \\ and Research branch, Islamic Azad \\ University, Ponak, Tehran, Iran; \\ ${ }^{2}$ Young researchers club - Islamic \\ Azad University, Tonekabon Branch, \\ Iran; ${ }^{3}$ Proteomics Research Center, \\ Faculty of Paramedical Sciences, \\ Shahid Beheshty University of Medical \\ Sciences, Tehran, Iran
}

\begin{abstract}
Imidazoles and their derivatives are compounds with chemotherapeutic applications. In this study, we investigated the chemical functionalization of carboxylated multiwalled carbon nanotubes (MWNT-COOH) by 1,2-phenylendiamine. Multiwalled nanotube (MWNT)-benzimidazole was obtained by an MWNT-amide reaction with $\mathrm{POCl}_{3}$ after 72 hours, which was confirmed by Fourier transform infrared, scanning electron microscopy, thermal gravimetric analysis, and elemental analysis. These functionalizations were chosen due to $-\mathrm{NH}_{2}$ and NHCO active sites in MWNT-amide for future application. Toxicity assays with fibroblast cells and MTT test for measurement of viable cell numbers were also performed. Cellular results did not show any toxicity change in modified samples from that of the reference samples.

Keywords: functionalization, 1,2-phenylendiamine, carboxylated multiwall nanotubes, toxicity
\end{abstract}

\section{Introduction}

Incorporation of imidazole and benzimidazole nuclei is an important synthetic strategy in drug discovery. ${ }^{1}$ Observations suggest that substituted benzimidazoles and related heterocycles, which are the structural isosteres of nucleotides owing to fused heterocyclic nuclei in their structures, allow them to interact easily with biopolymers, and possess potential activity with lower toxicity in the chemotherapeutic approach in man. ${ }^{2,3}$ The high therapeutic properties of related drugs have encouraged medicinal chemists to synthesize a large number of novel chemotherapeutic agents. The antitumoral activity of benzimidazole and its components have been reported in several studies. Furthermore, there are clinical anticancer drugs, known as Hoechst-33258 and Hoechst-33342 dyes, which include a benzimidazole structure., ${ }^{4,5}$ Carbon nanotubes have been attracting increasing attention from chemists and scientists owing to their electronic, mechanical, optical, and chemical characteristics.$^{6-8}$ Biomedical applications for MWNTs are being investigated actively because of their useful combination of size and physicochemical properties. ${ }^{9-13}$ In patients with cancer, MWNTs have potential roles in delivering pharmacologic agents, as diagnostic imaging agents, DNA, silent interfering RNA, oligonucleotides, and proteins to detect or treat cancerous cells. ${ }^{14-16}$ The application of functionalized carbon nanotubes as new nanovectors for drug delivery was apparent immediately after the first demonstration of the capacity of this material to penetrate into cells. Carbon nanotubes can be used to deliver their cargoes to cells and organs. Two papers ${ }^{17,18}$ detail the potential use of MWNTs to treat several types of cancer, with minimal or no toxic effects to normal cells.
Correspondence: Javad Azizian Department of Chemistry, Science and Research branch, Islamic Azad University, Ponak, Tehran, Iran

Tel $+98912 \mid 472035$

Fax +981924274409

Email j-azizian@cc.sbu.ac.ir 
Compounds such as imidazole are also well known antitumor agents. ${ }^{19-22}$ Carbon nanotubes also show good antitumoral effects. These materials can diffuse into cells and destroy DNA. Functionalization of carbon nanotubes with imidazole derivatives can leave mutual effects on cancerous cells. In recent years, chemical functionalization of carbon nanotubes has become more interesting because it allows modification of the nanotube surface for subsequent alignment. These surface modifications play an important role for application of nanotubes in composite sensors and many other fields. The chemical modifications of carbon nanotubes have been well summarized in several published review articles. ${ }^{23-29}$ Amines are among the reagents that have drawn the greatest attention. Haddon et al pioneered the approach of functionalizing the carboxylic groups of carbon nanotubes through amidation with amines bearing long alkyl chains. ${ }^{30-33}$ On the other hand, acid-chloride-functionalized carbon nanotubes are used for attaching glucosamine ${ }^{34}$ and didecylamine. ${ }^{35}$ Amidation of carbon nanotubes has also been carried out with aromatic amines. ${ }^{36-38}$ In this paper, we investigated the formation of a pentaheterocyclic, MWNTbenzimidazole, on MWNT nanotubes, in addition to developing the amidation of MWNT with bifunctional aromatic amines. Functionalized carbon nanotubes were characterized by Fourier transform infrared (FT-IR), scanning electron microscopy (SEM), thermal gravimetric analysis (TGA), elemental analysis, and toxicity assay.

\section{Materials and methods}

\section{Preparation of MWNT-amide}

MWNT-COOH 60 mg (20-30 nm; Netvino Co. Ltd) were sonicated in $90 \mathrm{~mL}$ of $\mathrm{N}, \mathrm{N}$-dimethyl formamide (DMF) for 45 minutes to give a homogeneous suspension. Oxalyl chloride $(2.5 \mathrm{~mL})$ was added dropwise to the MWNT suspension at $0^{\circ} \mathrm{C}$ under nitrogen. The mixture was stirred at $0^{\circ} \mathrm{C}$ for two hours and followed at room temperature for the same duration. Finally, the temperature was increased to $70^{\circ} \mathrm{C}$ and the mixture was stirred overnight to remove excess oxalyl chloride. 1,2-phenylendiamine $100 \mathrm{mg}$ dissolved in DMF was added to the MWNT suspension and the mixture stirred at $95^{\circ} \mathrm{C}$ for 72 hours. After cooling to room temperature, the mixture was filtered and washed thoroughly with DMF, ethyl alcohol, and tetrahydrofuran. Subsequently, the black solid was vacuum-dried at room temperature for five hours.

\section{Preparation of MWNT-benzimidazole}

MWNT-amide $30 \mathrm{mg}$ was mixed with $10 \mathrm{~mL} \mathrm{POCl}_{3}$ and then stirred at $80^{\circ} \mathrm{C}$ for 72 hours. After cooling to room temperature, the reaction mixture was separated by centrifugation and washed thoroughly with tetrahydrofuran. Thereafter, the solid obtained was vacuum-dried for four hours.

\section{Instrumental analysis}

All reagents and solvents (oxalyl chloride, 1,2-phenylendiamine, phosphoryl trichloride, and DMF) were obtained from Merck Chemical Inc. (Darmstadt, Germany), and MWCNT-COOH (95\% purity, 20-30 nm; Netvino Co. Ltd) were purchased and used as received. The FT-IR spectrum was recorded using $\mathrm{KBr}$ tablets on a Nexus 870 FT-IR spectrometer (Thermo Nicolet, Madison, WI). SEM was used to study the morphology of the WCNTs. SEM measurement was carried out on the XL30 electron microscope (Philips, Amsterdam, Netherlands). Elemental analyses of carbon, hydrogen, and nitrogen were performed using a Series II 2400 (Perkin Elmer, Waltham, MA). The samples were investigated by TGA (DuPont Instrument 951; DuPont, Wilmington, DE) in $\operatorname{air}\left(10^{\circ} \mathrm{C} / \mathrm{min}\right)$.

\section{Cytotoxicity analysis}

A fibroblast cell suspension (L929) from mouse tails was prepared according to ISO10993standards. The powders to control (TCPS) were well cleaned and sterilized by the autoclave method. Individual samples were placed in Petri dishes using a sterilized pincer; $3 \mathrm{cc}$ of the cell suspension were removed by pipette and poured into the control and experimental samples. Thereafter, all of the samples were separately placed in a Memmert incubator at $37^{\circ} \mathrm{C}$ for 24 and 48 hours. The samples in the polystyrene Petri dish were removed from the incubator after 24 and 48 hours and studied using a Eclipse TS-100 photonic microscope $(100 \times$; Nikon, Tokyo, Japan). Cell proliferation was determined by MTT assay for viable cell numbers. The MTT tetrazolium compound is reduced by living cells into a colored formazan product that is soluble in tissue culture medium. The quantity of formazan product is directly proportional to the number of viable cells in the culture. The assays were performed by adding $1 \mathrm{~mL}$ of MTT solution (Sigma, St. Louis, MO) and $9 \mathrm{~mL}$ fresh medium to each well after

Table I Elemental analysis of the modified multiwalled carbon nanotubes (MWNT)

\begin{tabular}{llll}
\hline MWNT & \%C & \%H & \%N \\
\hline $\mathrm{I}$ & 96.4 & 0.04 & 0 \\
2 & 89.7 & 1.31 & 2.09 \\
3 & 85.2 & 0.96 & 1.47 \\
\hline
\end{tabular}




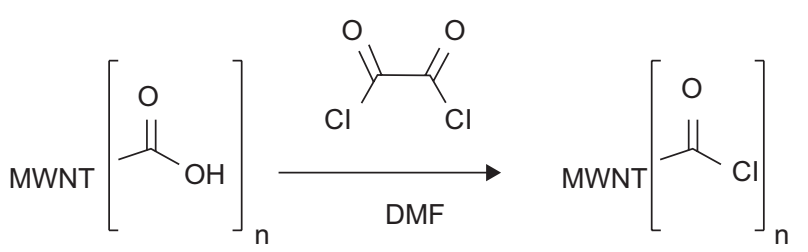

1

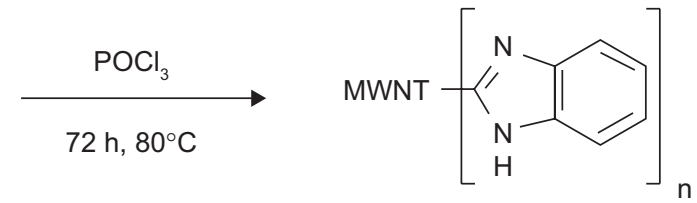

3

Figure I Synthesis route of the modified carboxylated multiwalled carbon nanotubes.

aspirating the spent medium and incubating at $37^{\circ} \mathrm{C}$ for four hours with protection from light. Colorimetric measurement of formazan dye was performed at a wavelength of $570 \mathrm{~nm}$ using a Rayto microplate reader.

\section{Results}

Elemental analyses of the modified MWNT 1-3 are shown in Table 1. Apart from the carbon values, the atomic percentages of hydrogen $1.31 \%$ and nitrogen $2.09 \%$ of 2 (as compared with 1 ) indicated that 1 is functionalized with 1,2-phenylendiamine. On the other hand, the percentage decrease in hydrogen from $1.31 \%$ to $0.96 \%$ confirms the five-ring formation. Based on these data, coupled with the assumption that the atomic percentages of nitrogen and hydrogen originated from the aromatic amine without elimination, we confirmed the functionalization of MWNT-COOH with 1,2-phenylendiamine.

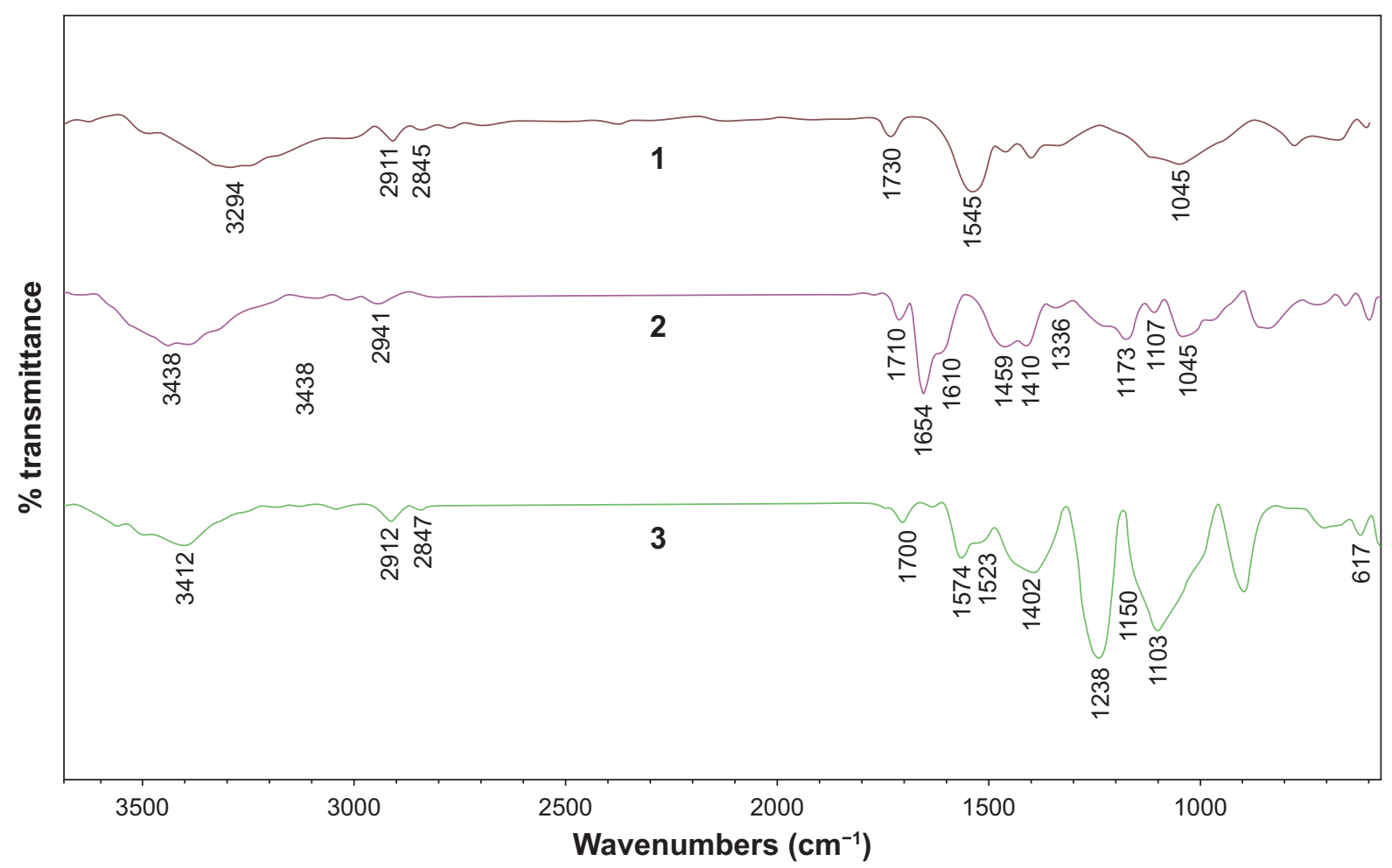

Figure 2 Fourier transform spectra (after baseline correction) of functionalized carbon nanotubes. I. carboxylated multiwalled carbon nanotubes, 2. multiwalled amide nanotubes, and 3. multiwalled benzimidazole nanotubes. 


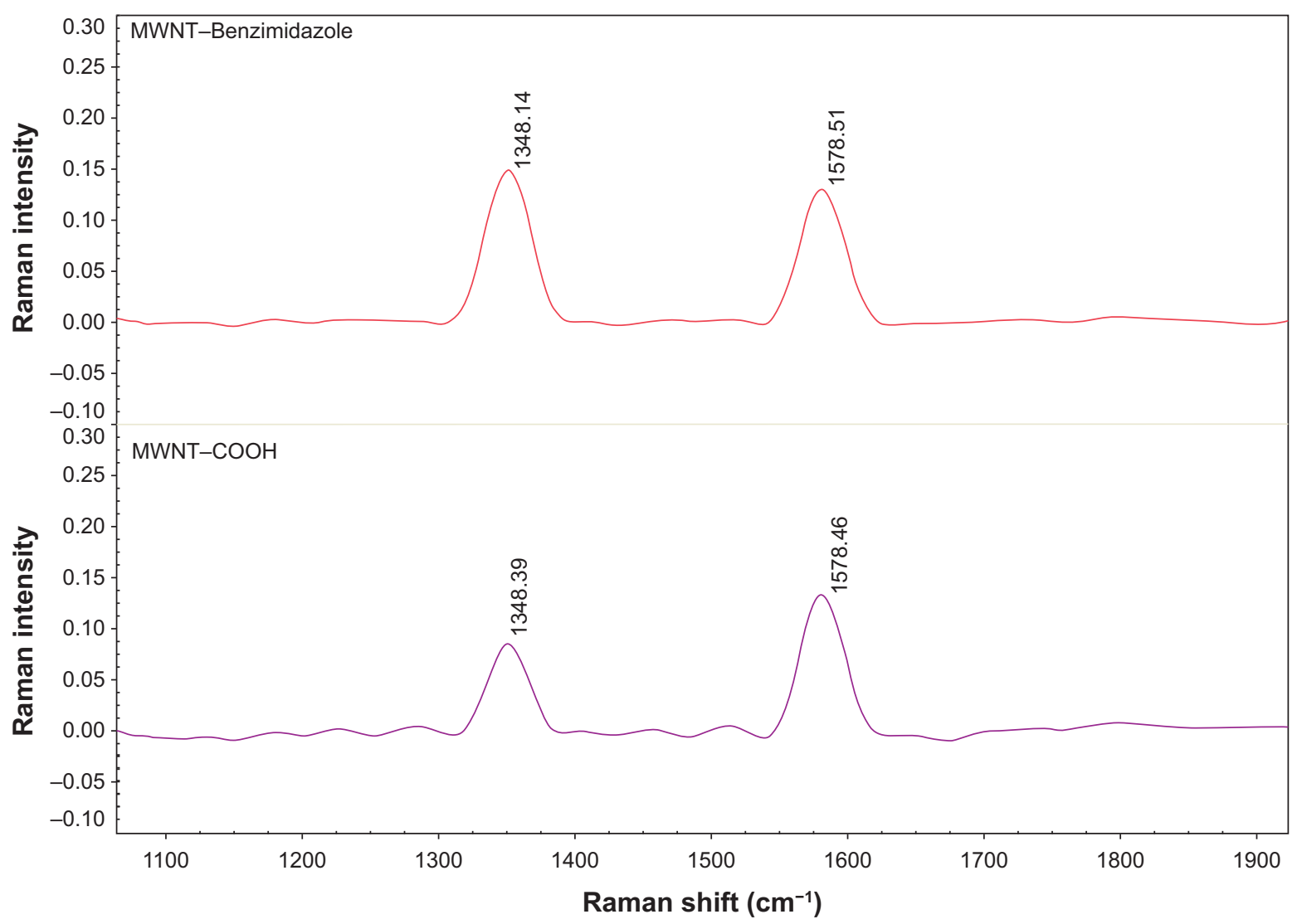

Figure 3 Raman spectra of carboxylated multiwalled carbon nanotubes and benzimidazole multiwalled carbon nanotubes.

Figure 1 shows the synthesis route of the modified MWNT-COOH.

Figure 2 shows the FT-IR spectrum of the modified MWNTs. In spectrum 1, the band at around $1550 \mathrm{~cm}$ corresponds to the stretching mode of the $\mathrm{C}=\mathrm{C}$ double bond that forms the framework of the carbon nanotube sidewall. ${ }^{24,25}$ The peak at 1730 and $1045 \mathrm{~cm}$ apparently corresponds to the stretching modes of the carboxylic acid groups. ${ }^{26}$ The two bands at $2800-2950 \mathrm{~cm}$ which are seen in all spectra are attributed to $\mathrm{CH}$ stretching of MWNT-COOH defects. In spectrum 2 , the new strong peaks at 3200-3500 can be assigned to the $\mathrm{N}-\mathrm{H}, \mathrm{NH}_{2}$, and $\mathrm{OH}$ stretching modes. The
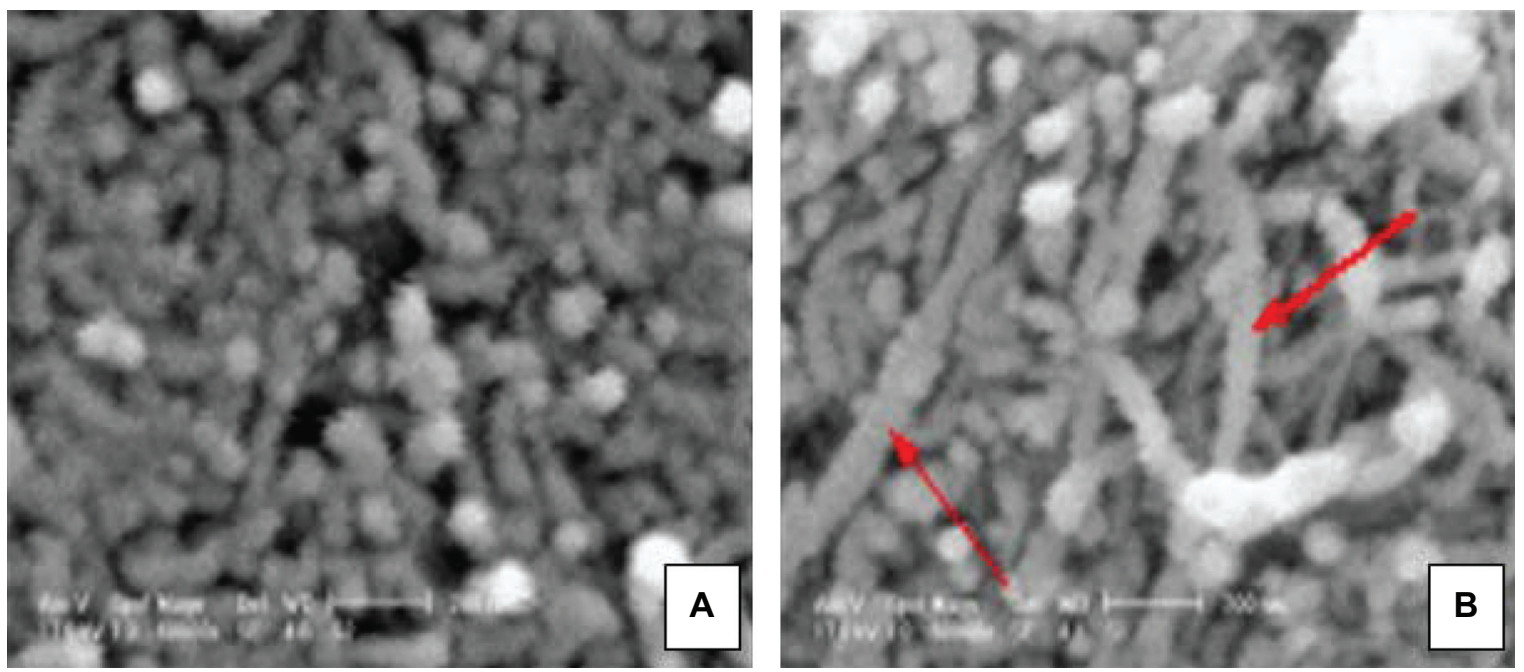

Figure 4 Scanning electron microscopy images of $\mathbf{A}$ carboxylated multiwalled carbon nanotubes and $\mathbf{B}$ benzimidazole multiwalled carbon nanotubes. 


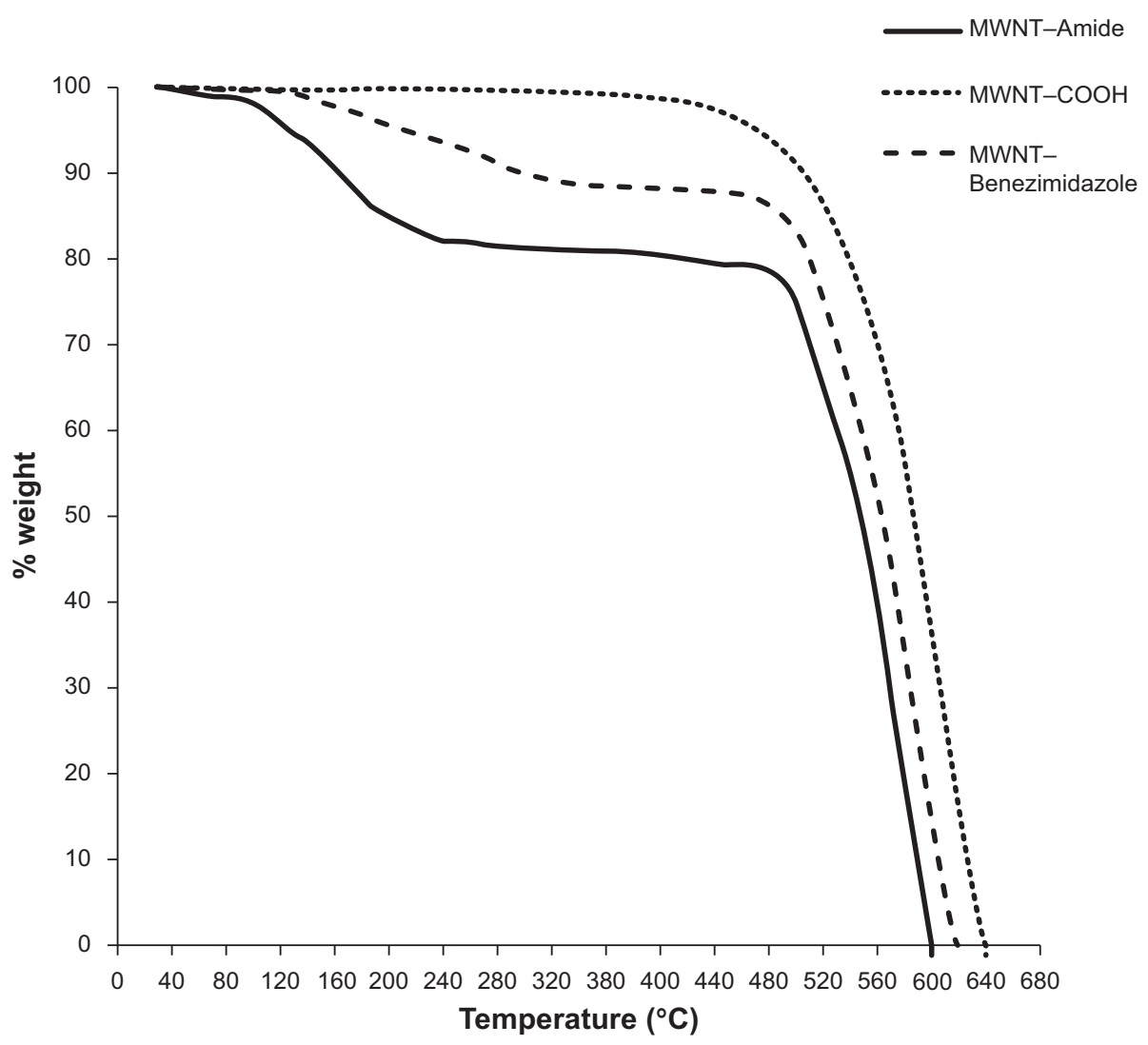

Figure 5 Thermal gravimetric analysis curves of modified multiwalled carbon nanotubes in air $\left(10^{\circ} \mathrm{C} / \mathrm{min}\right)$.

carbonyl peak in the spectrum 2 shift to $1654 \mathrm{~cm}$ (as compared with $1730 \mathrm{~cm}$ in spectrum 1$)$ is a result of amide $\mathrm{C}(=\mathrm{O})$ $\mathrm{NH}$ linkage formation. The other peak at around $1610 \mathrm{~cm}$ can be assigned to the $\mathrm{NH}_{2}$ scissoring mode ${ }^{27}$ in 2 that overlaps with the $\mathrm{C}=\mathrm{C}$ mode. The peaks at around 1520-1590, $1400-1480,1200-1350$, and $1100 \mathrm{~cm}$ correspond to $\mathrm{C}=\mathrm{C}$ stretching nanotubes, aromatic ring modes, and C-N and C-O stretching modes, respectively. In spectra 3, the peaks of the amide group disappear and three peaks at around 1580, 620, and $1150 \mathrm{~cm}$ appear which can be assigned to imidazole ring stretching. ${ }^{28}$ The two peaks at 1710 and $1700 \mathrm{~cm}$ in spectra 2 and 3, respectively, can be related to residual carboxylic acids on the nanotube. Thus, FT-IR spectra confirmed that MWNT$\mathrm{COOH}$ had been successfully modified by an aromatic amine.

Table 2 MTT analysis of the samples

\begin{tabular}{lll}
\hline Sample & $\lambda(\mathbf{n m})$ & Vialibility\% \\
\hline Control & 630 & 100 \\
MWNT-Amide & 317 & 50 \\
MWNT-Benzimidazole & 332 & 53 \\
MWNT-COOH & 347 & 55 \\
\hline
\end{tabular}

Raman spectroscopy is a powerful tool used to provide structural information about MWNT- $\mathrm{COOH}$ before and after functionalization. As shown in Figure 3, the D and $\mathrm{G}$ bands of the MWNT at around 1348 and $1578 \mathrm{~cm}$, attributed to defects, disorder-induced peaks, and tangential-mode peaks, ${ }^{29-31}$ can be clearly observed for both MWNT-COOH and MWNT-benzimidazole. Additionally, the intensity ratio $\left(\mathrm{I}_{\mathrm{D}} / \mathrm{I}_{\mathrm{G}}\right)$ of the $\mathrm{D}$ and $\mathrm{G}$ bands for MWNT-benzimidazole is 1.15 , which is greater than that for MWNT-COOH (0.64). The increase in intensity of the defect mode at $1348 \mathrm{~cm}$ was related to $\mathrm{sp}^{3}$ hybridization of carbon, and is used as an evidence of the disruption of the aromatic system of $\pi$ electrons by the attached molecules. ${ }^{29}$

More direct evidence for the functionalization of MWNTs comes from the SEM images. Figure 4 indicates that the MWNT-COOH has a smooth surface. The changes in morphology are remarkable. A uniform tubular layer due to a covalently bonded aromatic amine on the surface of the MWNT (the rough part) is observable. It seems that the diameters of MWNT-benzimidazole are slightly increased in comparison with MWNT-COOH. This may be due to 
interaction between the grafted molecules of benzimidazole. The third structure is quite different from those of the starting MWNT-COOH, in which the tube surface is relatively smooth and clean, as shown in Figure 4.

Figure 5 provides quantitative information on nanotube functionalization from the TGA results. In TGA graphs of MWNT-amide and MWNT-benzimidazole, two distinct decompositions are observable. The first one (below $360^{\circ} \mathrm{C}$ ) can be assigned to the aromatic amine and benzimidazole of MWNT-amide and MWNT-benzimidazole, respectively, while the second one (above $360^{\circ} \mathrm{C}$ ) is related to the nanotube as compared with the MWNT-COOH thermogram. If the mass loss of the MWNT-COOH at $360^{\circ} \mathrm{C}(0.88 \%)$ is used as the reference, the mass loss of functionalized MWNT by 1,2-phenylendiamine and benzimidazole of MWNT-amide and MWNT-benzimidazole at $360^{\circ} \mathrm{C}$ is about $19 \%$ and $11.4 \%$, respectively. These results indicate that there is one amide group for MWNT-amide per 47.9 and one benzimidazole group for MWNT-benzimidazole per 75.8 carbon atoms of MWNT, respectively. Figure 6 shows cellular images for this sample. Half of the cells in all three cases live. MTT analysis was also corroborated, as shown in Table 2.

\section{Conclusion}

In summary, we have introduced benzimidazole groups onto the surface of nanotubes via reaction of MWNT-amide with
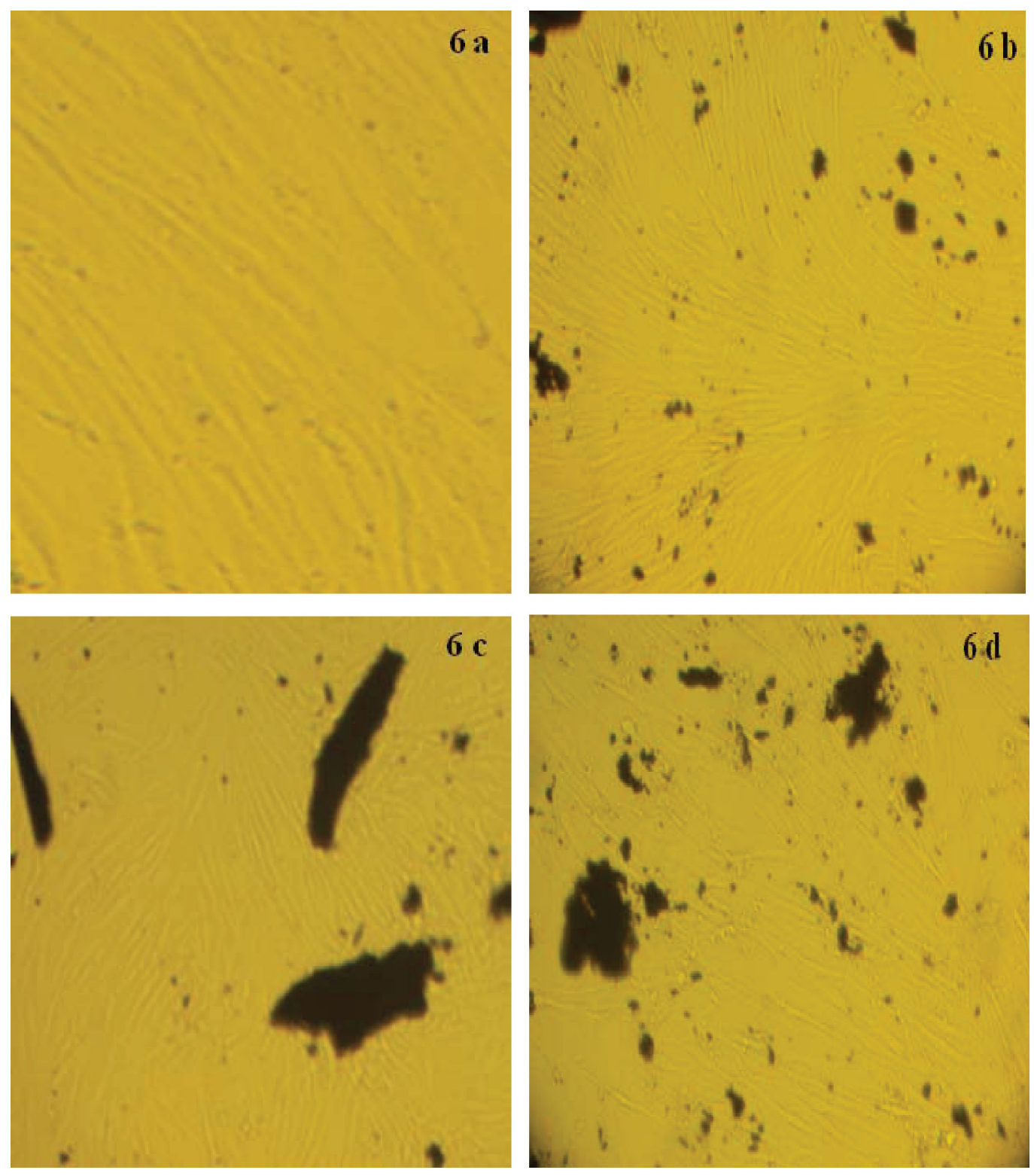

Figure 6 Cell growth on the samples. Control A) carboxylated multiwalled carbon nanotubes B) multiwalled benzimidazole carbon nanotubes C) and multiwalled amide carbon nanotubes $\mathbf{D})$. 
$\mathrm{POCl}_{3}$. Functionalization was demonstrated by their SEM images, as well as FT-IR, elemental analysis, and TGA. The results show successful functional groups and no change in toxicity in functional samples compared with the primary sample, with half of the cell growth on modified samples. In subsequent studies, antitumoral investigations of modified samples will be evaluated.

\section{Acknowledgment}

Funding for this research was provided by the Research Vice Presidency of Science and Research Branch, Islamic Azad University and Iranian Nanotechnology Initiative (Government of Iran).

\section{Disclosure}

The authors report no conflicts of interest in this work.

\section{References}

1. Townsend LB. Imidazole nucleosides and nucleotides. Chem Rev. 1967;67:533-563.

2. Haugwitz RD, Angel RG, Jacobs GA. Antiparasitic agents. 5. Synthesis and anthelmintic activities of novel 2-heteroaromatic-substituted isothiocyanatobenzoxazoles and benzothiazoles. J Med Chem. 1982;25: 969-974.

3. Hisano T, Ichikawa M, Tsumoto K, Tasaki M. Synthesis of benzoxazoles, benzothiazoles and benzimidazoles and evaluation of their antifungal, insecticidal and herbicidal activities. Chem Pharm Bull. 1982;30:2996-3004.

4. Kamal A, Ramul P, Srinivas Q, Ramesh G, Kumar PP. Synthesis of C8-linked pyrrolo[2,1-c][1,4]benzodiazepine-benzimidazole conjugates with remarkable DNA-binding affinity. Bioorg Med Chem Lett 2004; $14: 4791-4794$

5. Alper S, Temiz-Arpaci O, Aki-Sener E, Yalcin I. Some new bi-and ter-benzimidazole derivatives as topoisomerase I inhibitors. Farmaco. 2003;58:497-507.

6. Bonard J-M, Kind H, Stöckli T, Nilsson L-O. Field emission from carbon nanotubes: The first five years. Solid State Electron. 2001;45 893-914.

7. Baughman RH, Zakhidov AA, de Heer WA. Carbon nanotubes - the route toward applications. Science. 2002;297:787-792.

8. Avouris PH. Carbon nanotube electronics. Chem Phys. 2002;281:429.

9. Iijima S. Helical microtubules of graphitic carbon. Nature. 1991;354 56-58.

10. Bachtold A, Fuhrer MS, Plyasunov S. Scanned probe microscopy of electronic transport in carbon nanotubes. Phys Rev Lett. 2000; 84(26 Pt 1):6082-6085.

11. McEuen PL, Fuhrer MS, Park H. Single-walled carbon nanotube electronics. IEEE Trans Nanotech. 2002;1:78-185.

12. Durkop T, Getty SA, Cobas E, Fuhrer MS. Extraordinary mobility in semiconducting carbon nanotubes. Nano Lett. 2004;4: 35-39.

13. Bachilo SM, Strano MS, Kittrell C. Structure-assigned optical spectra of single-walled carbon nanotubes. Science. 2002;298: 2361-2366.

14. Zhang Z, Yang X, Zhang Y. Delivery of telomerase reverse transcriptase small interfering RNA in complex with positively charged singlewalled nanotubes suppresses tumor growth. Clin Cancer Res. 2006;12: 4933-4939.
15. Kam NW, O'Connell M, Wisdom JA, Dai H. Carbon nanotubes as multifunctional biological transporters and nearinfrared agents for selective cancer cell destruction. Proc Natl Acad Sci U S A. 2005;102: 11600-11605

16. Kam NW, Liu Z, Dai H. Functionalization of carbon nanotubes via cleavable disulfide bonds for efficient intracellular delivery of siRNA and potent gene silencing. J Am Chem Soc. 2005;127:12492-12493.

17. Gannon GI. Carbon nanotube-enhanced thermal destruction of cancer cells in a noninvasive radiofrequency field. Cancer. 2007;110: 2654-2655.

18. Liu Z, Sun X, Nakayama-Ratchford N, Dai H. The supramolecular chemistry of organic-inorganic hybrid materials. ACS Nano. 2007; 1:50-56.

19. Sava G, Bergamo A, Zorzet S, Gava B, Casarsa C. Influence of chemical stability on the activity of the antimetastasis ruthenium compound NAMI-A. Eur J Cancer. 2002;38:427-435

20. Keppler BK, Wehe D, Enders H, Rupp W. Syntheisis, antitumor activity, and X-ray structure of bis (imidazolium) imidazole-pentachloro ruthenate (III), (ImH)2 (RuImC15). Inorg Chem. 1987;26: 844-846.

21. Keppler BK, Rupp W, Juhl UM, Endres H, Nieu R, Blazer WS. Synthesis, molecular structure and tumor-inhibiting property of imidazolium-transbis(imidazole) tetra chlororuthenate (III) and its methyl substituted derivatives. Inorg Chem. 1987;26: 4366-4370.

22. Sava G, Gangliyardi R, Bergamo A, Alessio E, Mestroni G. Treatment of metastases of solid mouse tumors by NAMI-A; comparison with cisplatin, cyclophosphamide and decarbazine. Anticancer Res. 1999;19: 969-972.

23. Niyogi S, Hamon MA, Hu H, Zhao B, Bhowmik P, Sen R. Chemistry of single-walled carbon nanotubes. Acc Chem Res. 2002;35:1105-1113.

24. Hu C-Y, Xu Y-J, Duo S-W, Zhang R-F, Li M-S. One-step electrodeposited carbon nanotube/zirconia/myoglobin film. J Chin Chem Soc. 2009;56:234-238.

25. Holzinger M, Vostrowsky O, Hirsch A, Hennrich F, Kappes M, Weiss R. Sidewall functionalization of carbon nanotubes. This work was supported by the European Union under the 5th Framework Research Training Network 1999, HPRNT 1999-00011 FUNCARS. Angew Chem Int Ed Engl. 2001;40:4002-4005.

26. Sun YP, Fu K, Lin Y, Huang W. Functionalized carbon nanotubes: Properties and applications. Acc Chem Res. 2002;35: 1096-1104.

27. Banerjee S, Hemraj-Benny T, Wong SS. Covalent surface chemistry of single-walled carbon nanotubes. Adv Mater. 2005 ; 17:17-29.

28. Banerjee S, Kahn MGC, Wong SS. Rational chemical strategies for carbon nanotube functionalization. Chem Eur J. 2003;9:1898-1908.

29. Hirsch A. Functionalization of single-walled carbon nanotubes. Angew Chem Int Ed Engl. 2002;41:853-859.

30. Hamon MA, Chen J, Hu H, et al. Dissolution of single-walled carbon nanotubes. Adv Mater. 1999;11:834-8340.

31. Hamon MA, Hu H, Bhowmik P, et al. End-group and defect analysis of soluble single-walled carbon nanotubes. Chem Phys Lett. 2001; 347-348.

32. Chen J, Hamon MA, Hu H, et al. Solution properties of single-walled carbon nanotubes. Science. 1998; 282:95-98.

33. Zhao B, Hu H, Niyogi S, et al. Chromatographic purification and properties of soluble single-walled carbon nanotubes. J Am Chem Soc. 2001;123:11673-1167.

34. Pompeo F, Resasco DE. Water solubilization of single-walled carbon nanotubes by functionalization with glucosamine. Nano Lett. 2002;2; 369-373.

35. Liu L, Zhang S, Hu T, et al. Solubilized multi-walled carbon nanotubes with broadband optical limiting effect. Chem Phys Lett. 2002:359:191-195. 
36. Chen W-Y, Chen C-Y, Hsu K-Y, Wang C-C, Ling Y-C. Reaction monitoring of polyaniline film formation on carbon nanotubes with TOF-SIMS. Appl Surf Sci. 2004;231-2:845-849.

37. D'Este M, Nardi M, de Menna E. A co-functionalization approach to soluble and functional single-walled carbon nanotubes. Eur J Org Chem. 2006;11:2517-2522.
38. Kirikova MN, Ivanov AS, Savilov SV, Lunin VV. Modification of multiwalled carbon nanotubes by carboxy groups and determination of the degree of functionalization. Russ Chem Bull Int Ed. 2008;57(2):298-303.

\section{Publish your work in this journal}

The International Journal of Nanomedicine is an international, peerreviewed journal focusing on the application of nanotechnology in diagnostics, therapeutics, and drug delivery systems throughout the biomedical field. This journal is indexed on PubMed Central, MedLine, CAS, SciSearch $\AA$, Current Contents ${ }^{\circledR} /$ Clinical Medicine,
Journal Citation Reports/Science Edition, EMBase, Scopus and the Elsevier Bibliographic databases. The manuscript management system is completely online and includes a very quick and fair peer-review system, which is all easy to use. Visit http://www.dovepress.com/ testimonials.php to read real quotes from published authors.

Submit your manuscript here: http://www.dovepress.com/international-journal-of-nanomedicine-journal 